\title{
SOCIODEMOGRAPHIC CORRELATES OF BMI CATEGORIES AMONG FEMALE UNIVERSITY STUDENTS OF PRINCESS NOURAH BINT ABDULRAHMAN UNIVERSITY
}

Uzma Zaidi', Salwa Saad Awad, Eman Mortada Abdelsalam, Hind Diouri Qasem, Ghalia Fahad Kayal Princess Nourah Bint Abdulrahman University, Riyadh, Saudi Arabia

\section{ABSTRACT}

Purpose: Youth is considered a crucial period for launching positive health and social behaviours. It is a life stage when young people are experiencing rapid emotional, physical and intellectual changes, and when they begin the transition from childhood to adolescence to independent adulthood. The increasing prevalence of overweight and obesity worldwide urged the authors to study the sociodemographic factors that might work as causal factors for obesity among young Saudi female university students. The study aimed at unveiling the causes of obesity among this group and to find out the association of normal and overweight with socio-demographic variables.

Material and Method: A total of 500 female students were participated in this study from February to Novembers 2015 Weight and height were measured to determine the Body mass Index (BMI), the socio-demographic variables were examined by using sociodemographic form. Data was gathered from female students $(N=500)$ enrolled in bachelors program during the period of November 2014October 2015.

Results: The findings of the BMI measurements had shown that there is $54 \%$ of the university students were in the normal weight whose $\mathrm{BMI}$ is 24 or below and $35 \%$ were showing a BMI that is over 24 and were in the range of overweight or obesity.

Conclusion: This study concluded that there is an urgent need for guidance of university students regarding a healthy lifestyle and for fostering physical activity and nutrition programs on the campus to reduce and to keep the healthy weight.

\section{UDC \& KEYWORDS}

- UDC: 159.98 | BODY MASS INDEX | NORMAL WEIGHT - OVERWEIGHT ॥ SOCIO-DEMOGRAPHIC VARIABLES

\section{INTRODUCTION}

The prevalence of obesity has dramatically increased worldwide even it has reached epidemic proportions. Obesity in Saudi Arabia, is a growing health concern as it is increasing at an alarming rate, affecting virtually all ages and socioeconomic groups and is one of the leading causes of preventable deaths and disability. The prevalence of overweight and obesity has been doubled in the kingdom in about 10 years affecting more than $75 \%$ of the adult population in Saudi Arabia (El Mouzan et al., 2012; El-Hazm \& Warsy, 2002). Therefore, it is of national public health interest in the Saudi community.

World Health Organization in its report indicates that gulf countries have highest rate of obesity. Kuwait, Bahrain, Saudi Arabia and United Arab Emirates are in the list of top ten countries worldwide in term of obesity (Ono, Guthold \& Strong, 2005). Epidemiological research on obesity has focused on three specific areas: the sociodemographic and ' uazaidi@pnu.edu.sa lifestyle correlates of obesity, the health conditions and health status outcomes associated with excess weight and changes in the prevalence of obesity over time. Many cultural and social changes have been reported frequently in the Arabian Gulf region, due to oil discovery and economic growth during the 1970's and 1980's, that further could be associated with change in life style and eating patterns (Al-Rethaiaa, Fahmy \& Al-Shwaiyat, 2010; Rampersaud, Pereira, Girard, Adams, \& Metzl 2005; Antonio \& Chiara, 2005). All this situation has been seen as an alarming increase in obesity. One of the major causes of obesity is the changes in the diet.

The Kingdom of Saudi Arabia has witnessed significant lifestyle changes during the last four decades. Subsequently, physical inactivity, sedentary lifestyle, and an ever-increasing rate of obesity has become prevalent in Saudi society. Factor of obesity has been found among various Saudi population of children, adolescents, and adults. (Al-Hazzaa, 2007; Al-Hazzaa, 2004; El-Hazmi \& Warsy, 2002). One of the highly vulnerable population having unhealthy eating habits and having high in obesity was college students (Al-Rethaiaa, Fahmy \& Al-Shwaiyat, 2010; Huang, Harris, Lee, Nazir, Born \& Kaur, 2003). Numerous studies have demonstrated an association between body weight and eating behavior (Rampersaud et al., 2005) and cultural and socioeconomic factors also play an important role in the development of eating behavior (Tanofsky-Kraff, Cohen, Yanovski, Cox, Theim, Keil, Reynolds, \& Yanovski, 2006).

According to World Health Organization (WHO) obesity, has been defined as a body mass index (BMI) of $\geq 30 \mathrm{~kg} / \mathrm{m}^{2}$. $\mathrm{BMI}$ is the most frequently used and universally accepted measure is weight in relation to square of the individual's height and is the international guidelines to classify overweight and obesity (WHO, 2010). A high BMI has been linked to shorter life expectancy and risk of several comorbidities such as metabolic syndrome, osteoarthritis, sleep apnea, cardiovascular disease, hypertension, diabetes, dyslipidemia, and certain forms of cancer (Friedman \& Fanning, 2004). In addition to the broad range of obesity-related physiologic outcomes, it is associated with an increased risk of negative psychosocial functioning and increased psychological disorders for instance depression, bipolar disorder, panic disorder, and anxiety (Zhao, Ford, Dhingra, Strine, \& Mokdad, 2009). WHO (2014) has reported a huge number of death due to None Communicable Diseases (NCDs) during year 2012. The most threaten fact that obesity is the common factor associated with all these diseases.

As far as gender difference is concerned various studies revealed the higher proportion of female with obesity. Rasheed and Colleagues (1994), for the first time reported that female students were either overweight or obese in KSA. Another study conducted by Al Qauhiz (2010), has explored the dietary behaviour and lifestyle of Saudi female university students and reported an overweight and obesity

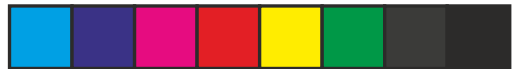


prevalence of $31.4 \%$ and $16.5 \%$ respectively. Additionally, a recent systematic review paper on obesity in Gulf Co-operation Council States which included 45 studies, reported that the prevalence of overweight and obesity in adults was $25-50 \%$ and $13-50 \%$ respectively, with a higher prevalence of obesity amongst females (Alhyas, Mckay, Balasanthiran \& Majeed, 2011).

Obesity is known as a multifaceted chronic disease involving environmental (social and cultural), genetic, physiological, metabolic and behavioural components. Environmental factor such as facilitating physical activity may improve health status (Kahn, 2002). More over healthy, natural and good quality of food can help to overcome the problem associated with poor quality of diet and food habits of Saudi youth (Washi \& Ageib, 2010). Researchers are privileged to serve at Princess Nourah Bint Abdulrahman University that is one of the largest Women only Universities. So, it was decided to conduct a study in various phases. Current work is second phase of the project. The aim of the study is to explore the sociodemographic correlates among normal weight and overweight female students of university.

\section{Data and Methodology}

The sample of this study was comprised of $(n=500)$ students enrolled in faculties of health science and humanity of Princess Nourah Bint Abdulrahman University. Respondents were approached from the health sciences Faculty $(n 1=250)$ and Humanities Faculty $(n 2=250)$ to gather the data and to provide the chance of equal representation. A request was forwarded to student registration office for the number of students enrolled at each college. Representative Sample was calculated by using statistical power analysis of sample size calculator by using $95 \%$ confidence interval. So, $\mathrm{N}=383$ was computed. In order to eliminate any problem in advance, related to completion and return of surveys, data was increased the sample up to 500. Female students enrolled in Bachelors Program of Health Sciences and Humanities having age range of 18-25 years were included. The mean age of the sample was 20.85 years with a standard deviation of 1.399 . All those colleges or programs were excluded who were offering any diploma program other than Bachelors program to avoided the variation in age range or physical growth effects.

\section{Instruments Used}

i. BMI Machine: BMI was measured by measuring weight and height of the students through BMI machine.

ii. Sociodemographic Information form: Measures that have been used for collecting the data of this study were the Sociodemographic Form that contains the personal characteristics of the participants, including age, the students' birth order, marital status, level of their university education, education level of father and mother and the students' residential status; whether living with their families or in a students' housing. The Princess Nourah University is considered the biggest university for women education in the Kingdom of Saudi Arabia and in the Gulf region. There for; it is expected to have students who live in the students hostel. The form also contained information of Health status other information. This section further measured the perception of health, frequency of involvement in physical exercise, self-image on five point rating scales.

\section{Ethical Considerations}

All the ethical considerations were fulfilled before conducting the study. After getting ethical approval from the Scientific
Council of University and concerned Heads of the Department, a consent form was given to the subjects to get their willingness to participate in the study. Researchers administered a brief structured interview to get the demographic information of the subjects and in order to screen them according to the research criteria. Participants were assured about confidentiality of their information.

Collected data was analyzed by using SPSS (V. 20). Descriptive Statistics have been drawn to present the data collected in simple percentages format to translate the relationship between the variables. The data will be presented in tables to show the frequency, percentages, mean and standard deviation. In some occasions a comparison was done to some characteristics of the samples that found from the study's participants who represent the two categories of BMI. Students whose BMI is in normal range $(18.5-24.9)$ and those whose $\mathrm{BMI}$ is over 25 their demographic information were compared. In the section below a discussion will follow the presentation of the statistical data. The findings will be discussed according to their significance to the issues presented.

\section{Results and Discussion}

Table 1: Descriptive Statistics of female Bachelors Program students of Health and Other Information $(\mathrm{N}=500)$

\begin{tabular}{|c|c|c|c|c|}
\hline Variable & $\mathbf{f}$ & $\%$ & Mean & $\begin{array}{c}\text { Std. } \\
\text { deviatio }\end{array}$ \\
\hline
\end{tabular}

\section{BMI}

\begin{tabular}{|c|c|c|c|c|}
\hline Underweight $=<18.5$ & 50 & 10 & \multirow{6}{*}{2.39} & \multirow{6}{*}{0.851} \\
\hline Normal weight $=18.5-24.9$ & 271 & 54.2 & & \\
\hline Overweight $=25-29.9$ & 114 & 22.8 & & \\
\hline Obesity = 30-39.9 Obese & 62 & 12.4 & & \\
\hline Morbid Obese $=40-50$ & 3 & 0.6 & & \\
\hline Super Obese $=50$ or above & 0 & 0 & & \\
\hline
\end{tabular}

Self-rated health status

\begin{tabular}{|l|l|l|}
\hline Poor & 8 & 1.6 \\
\hline Fair & 102 & 20.4 \\
\hline Good & 179 & 35.8 \\
\hline Very Good & 124 & 24.8 \\
\hline Excellent & 87 & 17.4 \\
\hline
\end{tabular}

Frequency of Physical activities

\begin{tabular}{|l|l|l|}
\hline (almost) every day & 59 & 11.8 \\
\hline 3-4 times a week & 95 & 19 \\
\hline once a week & 121 & 24.2 \\
\hline $1-3$ times a month & 78 & 15.6 \\
\hline less or never & 147 & 29.4 \\
\hline
\end{tabular}

Medical problems

\begin{tabular}{|l|l|l|l|l|}
\hline Yes & 91 & & & \\
\cline { 1 - 3 } No & 409 & & & \\
\cline { 1 - 3 }
\end{tabular}

Self-rated body image

\begin{tabular}{|l|l|l|l|}
\hline Poor & 17 & 3.4 \\
\hline Fair & 101 & 20.2 \\
\hline Good & 109 & 21.8 \\
\hline Very Good & 156 & 31.2 \\
\hline Excellent & 117 & 23.4 & \\
\hline
\end{tabular}

$\mathrm{f}=$ frequency, $\%=$ percentage, $\mathrm{M}=\mathrm{Mean}$ and $\mathrm{SD}=\mathrm{Standard}$ Deviation Source: Authors 


\begin{tabular}{|c|c|c|c|c|c|c|c|c|c|}
\hline Variable & $f$ & $\%$ & Mean & \begin{tabular}{|l|} 
Std. deviation \\
\end{tabular} & Variable & \multirow[t]{2}{*}{$f$} & \multirow[t]{2}{*}{$\%$} & \multirow[t]{2}{*}{ Mean } & \multirow[t]{2}{*}{ Std. deviation } \\
\hline $18-19$ years & 32 & 11.8 & & & Age & & & & \\
\hline $20-21$ years & 178 & 65.6 & 20.77 & 1.324 & $18-19$ years & 22 & 12.5 & 20.97 & 1.551 \\
\hline $22-23$ years & 51 & 18.8 & & & $20-21$ years & 98 & 55.6 & & \\
\hline $24-25$ years & 10 & 3.6 & & & $22-23$ years & 45 & 25.5 & & \\
\hline \multicolumn{5}{|l|}{ Birth Order } & $24-25$ years & 11 & 6.2 & & \\
\hline 1st Born & 53 & 19.5 & & & Birth Order & & & & \\
\hline Middle Born & 183 & 67.5 & & & 1 st Born & 42 & 23.8 & & \\
\hline Last Born & 35 & 12.9 & & & Middle Born & 109 & 61.9 & & \\
\hline Marital Status & & & & & Last Born & 25 & 14.2 & & \\
\hline Married & 32 & 11.8 & & & Marital Status & & & & \\
\hline Unmarried & 238 & 87.8 & & & Married & 25 & 14.2 & & \\
\hline Other (Divorced) & 1 & 0.3 & & & Unmarried & 150 & 85.2 & & \\
\hline Bachelors Level (Each level & stan & $s$ for $6 n$ & onths sem & ster) & Other (Divorced) & 1 & 0.5 & & \\
\hline First Year (Semester 2) & 60 & 22 & & & Bachelors Level (Each level & stand: & for $6 \mathrm{n}$ & nths sem & ster) \\
\hline 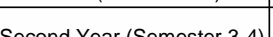 & 136 & 501 1 & & & First Year (Semester 2) & 51 & 28.9 & & \\
\hline secona rear (semester $\left.s^{-4}\right)$ & 130 & 50.1 & & & Second Year (Semester 3-4) & 79 & 44.8 & & \\
\hline Third Year (Semester 5-6) & 46 & 16.9 & & & Third Year (Semester 5-6) & 25 & 14.2 & & \\
\hline $\begin{array}{l}\text { Fourth Year (Semester 7-8) } \\
\text { Education of Father }\end{array}$ & 29 & 10.7 & & & Fourth Year (Semester 7-8) & 21 & 11.9 & & \\
\hline & 8 & 2.9 & & & Education of Father & & & & \\
\hline $\begin{array}{l}\mathrm{PhD} \\
\text { Masters }\end{array}$ & $\frac{8}{60}$ & \begin{tabular}{|l|}
2.9 \\
22.1 \\
\end{tabular} & & & $\mathrm{PhD}$ & 2 & 1.1 & & \\
\hline Bachelors & 58 & 21.4 & & & Masters & 33 & 18.7 & & \\
\hline A Level & 57 & 21 & & & Bachelors & 40 & 22.7 & & \\
\hline O Level & 42 & 15.4 & & & A Level & 37 & 21 & & \\
\hline Primary & 32 & 11.8 & & & O Level & 36 & 20.4 & & \\
\hline Nil & 14 & 5 & & & Primary & 24 & 13.6 & & \\
\hline Education of Mother & & & & & & 4 & 2.2 & & \\
\hline $\mathrm{PhD}$ & 1 & 0.3 & & & Education of Mother & & & & \\
\hline Masters & 34 & 12.5 & & & $\mathrm{PhD}$ & 0 & 0 & & \\
\hline Bachelors & 46 & 16.9 & & & Masters & 25 & 14.2 & & \\
\hline A Level & 51 & 18.8 & & & Bachelors & 18 & 10.2 & & \\
\hline O Level & 50 & 18.4 & & & A Level & 42 & 23.8 & & \\
\hline Primary & 54 & 19.9 & & & O Level & 32 & 18.1 & & \\
\hline Nil & 35 & 12.9 & & & Primary & 38 & 21.5 & & \\
\hline Residential status & & & & & & 21 & 11.9 & & \\
\hline Living with Family & 261 & 96.3 & & & Residential status & & & & \\
\hline Hostel & 10 & 3.6 & & & \begin{tabular}{|l} 
Living with Family \\
\end{tabular} & 175 & 99.4 & & \\
\hline Health & $\mathrm{h}$ and & ther $\operatorname{Inf}$ & mation & & Hostel & 1 & 0.5 & mation & \\
\hline Self-rated health status & & & & & Self-rated health status & Intur & (1) & intor & \\
\hline Poor & 2 & 0.7 & & & Poor & 3 & 1.7 & & \\
\hline Fair & 58 & 21.4 & & & Fair & 36 & 20.4 & & \\
\hline Good & 84 & 30.9 & & & Good & 69 & 39.2 & & \\
\hline Very Good & 78 & 28.7 & & & Very Good & 44 & 25 & & \\
\hline Excellent & 49 & 18 & & & Excellent & 24 & 13.6 & & \\
\hline Frequency of Physical activ & vities & & & & Frequency of Physical activ & vities & & & \\
\hline Every Day & 35 & 12.9 & & & Every Day & 19 & 10.7 & & \\
\hline 3-4 times/week & 53 & 19.5 & & & 3-4 times/week & 36 & 20.4 & & \\
\hline Once/week & 75 & 27.6 & & & Once/week & 37 & 21 & & \\
\hline 1-3 times a month & 32 & 11.8 & & & 1-3 times a month & 32 & 18.1 & & \\
\hline Less/ Not at all & 76 & 28 & & & Less/ Not at all & 52 & 29.5 & & \\
\hline Medical problems & & & & & Medical problems & & & & \\
\hline Yes & 20 & 7 & & & Yes & 31 & 17.6 & & \\
\hline No & 251 & 93 & & & No & 145 & 82.3 & & \\
\hline Self-rated body image & & & & & Self-rated body image & & & & \\
\hline Poor & 10 & 3.6 & & & Poor & 7 & 3.9 & & \\
\hline Fair & 49 & 18 & & & Fair & 39 & 22.1 & & \\
\hline Good & 39 & 14.3 & & & Good & 49 & 27.8 & & \\
\hline Very Good & 94 & 34.6 & & & Very Good & 51 & 28.9 & & \\
\hline Excellent & 79 & 29.1 & & & Excellent & 30 & 17 & & \\
\hline $\mathrm{f}=$ frequency, $\%=$ percenta & ge, $M$ & Mean & $\mathrm{d} \mathrm{SD}=\mathrm{St}$ & ndard Deviation & $\mathrm{f}=$ frequency, $\%=$ percenta & ge, $M=$ & Mean & $\mathrm{d} \mathrm{SD}=\mathrm{St}$ & ndard Deviation \\
\hline Source: Authors & & & & & Source: Authors & & & & \\
\hline
\end{tabular}


Table 1 shows the sociodemographic characteristic (age, birth order, marital status, level of education, father and mother education, residential status). The mean age of the sample was 20.85 years. Which reflect on the ordinary age for female to be enrolled in the university level. The majority of participants were unmarried which represents $(89.2 \%)$ and the majority are living with their families (97.4\%). Unmarried Muslim females are expected to stay in the family home and cannot move to live independently unless getting married. It worth highlighting that the traditional Muslim family is extended, often containing three or more generations (Anwar, 1994). An extended structure offers many advantages, including stability, consistency, and physical and psychological support, particularly in times of need. Being in the family home has many advantages to live in a luxurious life style that includes being well served in all aspects of daily routines. Several studies have underlined the importance of socioeconomic factors and physical activity (Aal-Isa, 1999). El Rhazi and Colleagues (2010), showed that family income was strongly and positively associated with obesity. This confirms that students who live with their families are in a better socioeconomic status which adds to their sedentary life style and to have access to more varieties of dietary resources and lifestyle choices which provides the opportunity to seek dining outside in restaurants where fast food is usually served. This confirmed by the factors that include the changes in social and cultural environments, education, physical activity, diet and nutrition, and difference in income and time expenditure (Musaiger, 2004).

As far as birth order (Table $2 \& 3$ ) is concerned the only prominent frequency was found among those who were middle born. Percentage of students who are overweight/obese was $23.8 \%$ for those who were $1^{\text {st }}$ born. And then $61.9 \%$ for those who were in the middle among their siblings. It is unlike in other studies that revealed the last born or the only children were obese/ overweight. This was due to the maternal ambivalence that associated with overfeeding and obesity. There is an implication that first born children receive special treat from their parents which might result in overfeeding them when they were children and will lead to obesity during adulthood.

The high prevalence of overweight/obesity among this study sample might be due to less physical activity and higher consumption of more unhealthy, high fat foods, sweets/candies and salty snacks (Al-Rukban, 2003). Data that support this finding derived from a limited number of studies show that $60 \%$ of Saudi children and $71 \%$ of young people do not participate in physical activity regularly and for considerable duration (Al-Hazzaa, 2004; Al-Hazzaa, 2002).

Generally, Saudi young people do not consider physical activities as a favourable pursuit for leisure time activities. The environmental factors are also discouraging that there is lack of recreational facilities. One of the major reason of not actively participating of youth in physical activity might be the extreme hot weather prevail throughout the year. Moreover geographical location of desert formulate it more intense. Although much of the development with new parks and outdoor facilities for exercise have been provided by the government all over the country. The extreme weather usually restrict for indoor facilities for exercise (Mozaffarian et al., 2012). It is confirmed that the regular physical activity is a factor that leads to energy expenditure and is therefore essential to energy balance, weight control and prevention of obesity (WHO, 2010). Therefore it is extremely important to work on intervention measures that will help in having healthier and productive generations.

The findings of this study showed that students do not pay much attention to their weight or BMI level. This results in the fact that they do not recognize obesity as a risk factor for life-threatening conditions like cardiovascular disease, hypertension and diabetes. This finding questions the old socio-cultural notion that is female fatness is still viewed as a sign of social status and is considered a cultural symbol of beauty, fertility and fortune? Cultural ideals influence how people assess their body image and body weight (Swami, Fredrick, Aavik, Alcalay, Allik, \& Anderson 2010; Duda, Jumah, Hill, Seffah, Biritwum, 2007). A major issue associated with overweight and obesity is the perception of body size in different cultural settings (George \& Franko 2010; Wardle, Haase, \& Steptoe, 2006). It is also confirmed by Ross (1994) that the individuals' opinions of themselves are a reflection of the way that others perceive them. If the students' receive a negative societal views regarding their weight then it will be expected that their views about themselves will also be negative, which might lead to reduced self-esteem and increased symptoms of depression.

A major issue associated with overweight and obesity is the perception of body size in different cultural settings (George et al, 2010; Wardle, et al 2006). Our study used a questionnaire of body images to estimate self-reported body size and a scale to measure the BMI. Differences between objective measures of body size (i.e., BMI) and individual perception of current body image suggest individual or societal definitions of desirable or "normal" body size that are not based on medical facts. The findings of this study found that $28.9 \%$ of students have rated their perception with regards to their bodies as very good, $27.8 \%$ as good and $22.1 \%$ as average and $17 \%$ as excellent and only $3.9 \%$ of the subjects studied perceived their body image as poor. These findings suggest that most of these young women do not acknowledge their extra weight and the related health risks. It is well known that perception of body-weight status plays an important role in weight management (Riley, Bild, Cooper, Schreiner, Smith, Sorlie, Thompson, 1998). This underestimation of their body weight might lead to the prevalence of many health problems that are related to obesity or overweight. Previous research that has studied the relationship between body mass index and self-esteem did not reach a unanimous agreement on the existence of a negative relationship. Thus, Mendelson, Mendelson and Andrews (2000), investigated the relationship between obesity, self-esteem and body self-esteem and demonstrated a lack of association between body weight and self-esteem, unlike between body weight and body esteem. To the contrary of previous study, Webber (2006), states that body mass is an important aspect of social acceptance and overweight is an important predictor of poor self-esteem.

\section{Limitations and Suggestions}

This research based on the data of 500 female students. The sample of male students, adults and community can be included for future study to get generalization of the findings. It is recommended for the future studies to include the food choice along with BMI in order to enhance scope of study.

\section{CONCLUSION}

This study has established the relative importance of young people overweight/obesity as a health problem in the university and identified key factors that influence their overweight/obesity and physical activity behaviours. These 
findings concreted the understanding for the development of intervention programs and enable focusing on the resources on key areas of need, such as support and education for overweight/obese students, their participation in physical activity, time spent watching TV, and promoting physical activity, abolishing sedentary behaviours, and enhancing students' healthy nutrition. The results of this investigation can be used to emphasize on the importance of enhancing the students' health well being by establishing university educational programs that can work on the importance of weight reduction and healthy nutrition by using the preventive measures to avoid any kind of pathological conditions that these young women might experience.

\section{Acknowledgements}

Research project was funded by Princess Nourah Bint Abdulrehman University. We would like to thank Scientific Research Council of PNU, Students Registration office, Scientific Research committee for CHRS and all the colleges and departments for their support with data collection.

\section{REFERENCES}

Aal-Isa, A. N. (1999). Dietary and socio-economic factors associated with obesity among Kuwaiti college men. British Journa of Nutrition, 82, 369-374.

Al-Hazzaa, H. (2004). Prevalence of physical inactivity in Saudi Arabia: a brief review. East Mediterranean Health Journal, 10, 663-670.

Al-Hazzaa, H. M. (2002). Physical activity, fitness and fatness among Saudi children and adolescents: implications for cardiovascular health. Saudi Medical Journal, 23, 144-150.

Al-Hazzaa, H. M. (2007). Rising trends in BMI of Saudi adolescents: evidence from three national cross sectional studies, Asia Pacific Journal of Clinical Nutrition, 16 (3), 462-466.

Alhyas, L., McKay, A., Balasanthiran, A., \& Majeed, A. (2011) Prevalence of overweight, obesity, hyperglycaemia, hypertension and dyslipidaemia in the Gulf: Systematic review. Journal of the Royal Society of Medicine, 2(7),55. DOI: 10.1258/shorts.2011. 011019.

Al-Qauhiz, N. M. (2010). Obesity among Saudi female university students: Dietary habits and health behaviours. Journal of Egypt Public Health Association, 85, 45-59. 46.

Al-Rethaiaa, A. S., Fahmy A. A., \& Al-Shwaiyat, N. M. 2010. Obesity and eating habits among college students in Saudi Arabia: a cross sectional study. Nutrition Journal. 9: 39. DOI: 10.1186/1475-28919-39.

Al-Rukban, M. O. (2003). Obesity among Saudi male adolescents in Riyadh, Saudi Arabia. Saudi Medical Journal, 24: 27-33.

Antonio, G., \& Chiara, P. A. (2005). A Natural Diet Versus Modern Western Diets? A New Approach to Prevent "Well-Being Syndromes". Digestive Diseases and Sciences, 50(1): 1-6.

Anwar, M. (1994). Young Muslims in Britain: Attitudes, Educational Needs, and Policy Implications. Leicester: Islamic Foundation.

Duda R. B., Jumah, N. A., Hill, A. G., Seffah, J., \& Biritwum. R. (2007). Assessment of the ideal body image of women in Accra, Ghana. Tropical doctor; 37(4): 241-4

El Mouzan, M. I., Al Herbish, A. S., Al Salloum, A. A., Al Omar, A. A., \& Qurachi, M. M. (2012). Regional variation in prevalence of overweight and obesity in Saudi children and adolescents. Saudi Journal of Gastroenterology, 18: 129-32.

El-Hazmi, M. A. \& Warsy, A. S. (2002). A Comparative Study of Prevalence of Overweight and Obesity in Children in Differen Provinces of Saudi Arabia. Journal of Tropical Pediatrics, 48(3) 172-177.

El-Rhazi, K., Nejjari, C., Zidouh, A., Bakkali, R., Berraho, M., \& Barberger Gateau P. (2010). Prevalence of obesity and associated sociodemographic and lifestyle factors in Morocco. Public Health Nutrition, 14(1), 160-167 DOI: 10.1017/S1368980010001825.

Friedman, N., \& Fanning, E. (2004). Overweight and obesity: an overview of prevalence, clinical impact, and economic impact. Disease Management 7 (1): S1-S6.

George, J. B. \& Franko, D. L. (2010). Cultural issues in eating pathology and body image among children and adolescents. Journal of Pediatric Psychology; 35(3): 231-42.

Huang, T. T., Harris, K. J., Lee, R. E., Nazir. N., Born, W., \& Kaur, H. (2003). Assessing Overweight, Obesity, Diet, and Physical Activity in College Students. Journal of American College of Health, 52(2): 83-86

Kahn, E. B., Ramsey, L. T., Brownson, R. C., Heath, G. W., Howze, E. H., \& Powell, K.E. (2002). The effectiveness of interventions to increase physical activity. A systematic review. American Journal of Preventive Medicine; 22 (4 Suppl): 73-107.

Mendelson, M. J., Mendelson, B. K., \& Andrews, J. (2000). Selfesteem, body-esteem and body-mass in late adolescents; is a complex $x$ importance model needed?. Journal of Applied Developmental Psychology, 21, 249-266.

Mozaffarian, D., Afshin, A., Benowitz, N. L., Bittner, V., Daniels, S. R., Franch, H. A., Jacobs, D. R., Jr, Kraus, W. E., Kris-Etherton, P. M., Krummal, D. A., Popkin, B. M., Whitsel, L. P., Zakai, N. A. (2012). Population approaches to improve diet, physical activity, and smoking habits: a scientific statement from the American Heart Association. Circulation. 126: 1514-63.

Musaiger, O. (2004). Overweight and obesity in the Eastern Mediterranean Region: can we control it? Eastern Mediterranean Health Journal. 10(6): 789-793.

Ono, T., Guthold, R., Strong, K., WHO, Global Comparable Estimates (2005). available from URL, https://apps.who.int/ infobase/Comparisons.aspx

Rampersaud, G. C., Pereira, M. A Girard, B L Adams, J. \& Metzl, J. D. (2005). Breakfast habits, nutritional status, body weight, and academic performance in children and adolescents. Journal of the American Dietetic Association, 105: 743-760, quiz $761-762$

Rasheed, P., Abou-Hozaifa, B. M., \& Kahn, A. (1994). Obesity among young Saudi female adults: a prevalence study on medical and nursing students. Public Health, 108, 289-294.

Riley, N. M., Bild, D. E., Cooper, L., Schreiner, P., Smith, D. E., Sorlie, P., \& Thompson, J. K. (1998). Relation of self-image to body size and weight loss attempts in black women: the CARDIA study. Coronary Artery Risk Development in Young Adults. American Journal of Epidemiology. Dec 1; 148(11): 1062-8.

Ross, C. E. (1994). Overweight and depression Journal of Health and Social Behavior, 35 (1), 63-79.

Swami, V., Frederick, D. A., Aavik, T., Alcalay, L., Allik, J., \& Anderson, D. (2010). The attractive female body weight and female body dissatisfaction in 26 countries across 10 world regions: results of the International Body Project I. Personality and Social Psychology Bulletin; 36(3): 309-25.

Tanofsky-Kraff, M., Cohen, M. L., Yanovski, S., Cox, C., Theim, K., Keil, M., Reynolds, J. \& Yanovski, J. (2006). A prospective study of psychological predictors of body fat gain among children at high risk for adult obesity. Pediatrics, 117: 1203-1209.

Wardle, J., Haase, A. M., \& Steptoe, A. (2006). Body image and weight control in young adults: international comparisons in university students from 22 countries. International Journal of Obesity (Lond); 30(4): 644-51

Washi, S. A., \& Ageib, M. B. (2010). Poor diet quality and food habits are related to impaired nutritional status in 13- to 18year-old adolescents in Jeddah. Nutrition Research., 30, 527534.50 .

Webber, B. A. (2006). A South African study of the association between global self-esteem and Body Mass Index scores, in adolescent females: An investigation of differences in perceived weight problems, racial identity, physical exercise, weight control behavior and stage of pubertal development, University of Witwatersand, Johanesburg, 10-31.

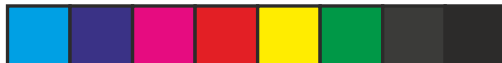


SOCIODEMOGRAPHIC CORRELATES OF BMI CATEGORIES AMONG FEMALE UNIVERSITY STUDENTS OF PRINCESS NOURAH BINT ABDULRAHMAN UNIVERSITY

World Health Organization (2014). Global Health Estimates: Deaths by Cause, Age, Sex and Country, 2000-2012. Geneva.

World Health Organization. (2010). World Health Organization Global database on body mass index. Retrieved from www.apps.who.int/bmi/index.jsp

Zhao, G., Ford, E. S., Dhingra, S., Li, C., Strine, T. W., \& Mokdad,

A. H. (2009). Depression and anxiety among US adults: associations with body mass index. International Journal of Obesity, 33: $257-266$ 